\title{
A REPRESENTAÇÃO DO OUTRO NO CINEMA FANTÁSTICO: O CASO DE A FORMA DA ÁGUA (2017), DE GUILLERMO DEL TORO
}

Alexander Meireles da Silva (UFG) Gabriela Spinola Silva (UFG)

Recebido em 04 nov 2018. Alexander Meireles da Silva é Doutor em Literatura Aprovado em 11 mar 2019.

Comparada (UFRJ). Está vinculado à UFG-Regional Catalão, onde atua na Graduação em Letras - Curso de Português, Curso de Português e Inglês e no Mestrado em Estudos da Linguagem. Produção bibliográfica: Capítulo de livro - a modernidade monstruosa de $\mathrm{H}$. P. Lovecraft em A sombra de Innsmouth" (As nuances do gótico: do setecentos à atualidade / 2017); Capítulo de livro - "A nossa guerra dos mundos: $\mathrm{H}$. G. Wells e a marginalização do povo no Fantástico brasileiro" (Tessituras literárias: Cultura, identidade e outras artes / 2017); Livro - Literatura Inglesa para brasileiros: curso completo de literatura e cultura inglesa para estudantes brasileiros (2005). É Membro do Grupo de Pesquisa Estudos do Gótico; Membro do Grupo de Pesquisa Nós do Insólito; Membro do GT ANPOLL Vertentes do Fantástico Ficcional. Suas áreas de interesse de pesquisa se concentram na Fantasia, Gótico, Horror, Ficção Científica e Weird Fiction. Lattes: $\quad$ http://lattes.cnpq.br/8325920517508979. Página pessoal: www.fantasticursos.com. Canal: https://www.youtube.com/fantasticursos E-mail: prof.alexms@gmail.com 
Gabriela Spinola Silva é Bacharel em Tradução pela Universidade Federal de Uberlândia (2017), atualmente mestranda em Estudos da Linguagem na UFG/RC, com pesquisa sobre tradução intersemiótica. Seus trabalhos mais pertinentes são: "Pelo direito de desobedecer: o filme 'Disobedience', de Sebastián Lelio, como tradução intersemiótica do livro homônimo de Naomi Alderman", apresentado em simpósio na III Feira Literária de Catalão e I Congresso de Leitura e Literatura Contemporânea (2018); e "O palavrão em Deadpool: Uma análise comparativa entre legendas oficiais e legendas de fãs", apresentado em conjunto com Francine de Assis Silveira na XXXVII Semana do Tradutor e II Simpósio Internacional de Tradução (2017). Participante do grupo de pesquisa "Do Fantástico aos fantásticos: Facetas do Insólito na Contemporaneidade". Áreas de interesse de pesquisa são Tradução Audiovisual, Tradução Intersemiótica e Literatura Fantástica. Lattes: http://lattes.cnpq. br/9286192559852580 E-mail: tradspinola@gmail.com

Resumo: Desde a sua gênese, o Cinema tem servido como veículo para a manifestação das ânsias que consomem as mais diversas sociedades que dele se valem. Uma das mais peculiares formas dessas manifestações é o Cinema Fantástico - no qual, através da apresentação de criaturas monstruosas ou maravilhosas, submundos incríveis, universos paralelos e galáxias distantes, é possível ver a inserção do Outro e das visões que os respectivos realizadores dos filmes (tal qual a sociedade em que estivessem inseridos) têm a respeito destes (INAYATULLAH e BLANEY, 2004; TODOROV, 1999). Um exemplo desta questão, logo nos primórdios da sétima arte, é o clássico Viagem à Lua (1902), de Georges Méliès, o qual traz os selenitas - as criaturas que habitam a Lua - trajando vestimentas tribais, lanças e expressões similares a demônios, em uma escolha de indumentária remetente aos nativos das colônias francesas na África no final do século XIX e 
início do século XX. Desta forma, o presente artigo busca discorrer sobre a representação do Outro ao longo da história do cinema mainstream ocidental, e traçar uma análise a respeito de como todos os personagens do filme A forma da água (2017), de Guillermo del Toro ${ }^{1}$, em especial a criatura anfíbia monstruosa no centro da narrativa, refletem tais questões acerca da alteridade. Palavras-chave: Alteridade; Cinema Fantástico; $A$ Forma da Água.

Abstract: Ever since its first baby steps, Cinema has been an outlet for Humanity's greatest anxieties. One of the many peculiar ways these anxieties have been put out is in fantasy films. Through its monstruous and marvellous creatures, astonishing underworlds, parallel universes and galaxies far, far away, we are presented to the Other and to the views the filmmakers (and the societies they are inserted in) have of them (INAYATULLAH e BLANEY, 2004; TODOROV, 1999). In the dawn of cinema, the classic $A$ trip to the Moon (1902), directed by Georges Méliès, is a prime example of this. It brings out the selenites (the living creatures that inhabit the Moon) dressed in tribal garments, bearing spears and with faces similar to devils, in a very clear reference to the French colonies in Africa by the end of the 19th century and the beginning of the 20th century. Therefore, this work intends to dwell on how the Other has been represented throughout mainstream ocidental Cinema history, and to analyze how all the main characters in The shape of water (2017), directed by Guillermo del Toro, reflect such questions regarding otherness, particularly when it comes to each of their relationships to the monstruous amphibian creature the movie's plot revolves around.

Keywords: Otherness; Fantasy Films; The Shape of Water.

1 IMDB. Guillermo del Toro. In https://www.imdb.com/name/nm0868219/?ref_=tt_ov_ dr. Acesso em 01.Nov.2018. 


\section{INTRODUÇÃO: UMA CONTEXTUALIZAÇÃO HISTÓRICA}

Nascido nos estertores do século XIX, o Cinema surgiu como evidência dos efeitos da Revolução Industrial sobre diversas esferas da experiência humana na Era Vitoriana, se colocando como uma nova expressão artística fomentada pela demanda de atendimento dos desejos da massa pelo novo e da reprodutibilidade da arte. Como tal, em seus primeiros momentos o Cinema trouxe um alinhamento com todo o discurso vigente ao longo do século XIX, marcado pelo Imperialismo, o impacto das ideias de Charles Darwin sobre a evolução das espécies e sua aplicabilidade em outros campos sociais e as pesquisas sobre a mente humana. Estes fatores alimentaram debates políticos, teológicos, científicos que capturaram a imaginação de escritores na criação de mundos imaginários habitados por seres fantásticos. Logo, duplos emergindo da psique de cavaleiros distintos (O estranho caso de Dr. Jekyll e Mr. Hyde, 1886), vampiros aristocratas oriundos do leste europeu (Drácula, 1897), criaturas bestiais antropomórficas, resultado de experiências insanas (A ilha do Dr. Moreau, 1896), ou marcianos invasores na Londres finissecular (Guerra dos mundos, 1897) surgiram na literatura fantástica da época, fornecendo também matéria prima para o nascente Cinema. Percebe-se aí que a inserção do Outro no cinema se deu pela apresentação de monstros dos mais diversos tipos - alienígenas, criaturas mitológicas, mutantes, vampiros e outros seres. De fato, a forma como o autor de uma narrativa (seja ela cinematográfica, literária, quadrinhística ou como for) escolhe, deliberadamente, representar o Outro, costuma dizer mais sobre o próprio autor e seu contexto histórico-cultural do que necessariamente sobre o Outro propriamente dito. 
Neste sentido, este trabalho tem como objetivo analisar como a criatura monstruosa apresentada na produção cinematográfica A forma da água (2017), dirigida por Guillermo del Toro, se coloca como um espelho a partir do qual outros personagens encontram sua própria monstruosidade moral e social.

Tome-se como exemplo a produção Viagem à Lua (1902), de Georges Méliès, baseado nos romances Da Terra à Lua (1877), de Júlio Verne e Os primeiros homens na Lua (1901), de H. G. Wells. Ainda que o filme A conquista do ar (1901), de Ferdinand Zecca seja a obra pioneira de Ficção Científica no Cinema, foi a produção de George Mèliés que se tornou um marco para a História do Cinema por ser a primeira obra cinematográfica a usar "efeitos especiais" (técnicas de stop-motion que foram resultado de anos de prática de Méliès como ilusionista) (SCHOEREDER, 1986, p.24). O filme traz os selenitas - criaturas que habitam na Lua - representados com vestimentas caracterizando-os como demônios e utilizando lanças. Essa escolha de indumentária é interpretada largamente como sendo uma referência aos nativos das colônias da França na África durante o final do século XIX e início do século XX.

Já durante o período entreguerras, é por meio do Fantástico que o Cinema começa a se desvincular da imagem de produto de mero entretenimento para as massas para começar a mostrar o seu amadurecimento enquanto veículo das ansiedades de suas sociedades, algo expresso no surgimento do Expressionismo Alemão. Nascida no universo das Artes Plásticas, esta expressão artística capturou o espirito de ceticismo, desencanto e pessimismo prevalente na Alemanha após a sua derrota na Primeira Grande Guerra, gerando um grau de incerteza sobre o futuro e sobre a 
autonomia do indivíduo dentro de um sistema em que ele se via vítima de forças superiores a ele; forças estas que provocavam uma crise identitária traduzida em personagens vítimas de hipnotizadores (O gabinete do Dr. Caligari, 1920), vampiros (Nosferatu, 1922) ou cientistas loucos (Metrópolis, 1927).

Com $O$ Gabinete do doutor Caligari, o cinema fantástico deslanchou - especialmente na Alemanha do pós-guerra. Os cenários distorcidos, expressionistas, do filme, que rejeitavam qualquer pretensão de realismo, a narrativa fragmentada, as atuações hiperestilizadas e a sensação de insegurança paranoica se uniam para expressar a atmosfera de uma nação derrotada, traumatizada, sem confiança na própria identidade, vendo inimigos tanto internos quanto externos. As sombras pintadas deste filme e dos seus sucessores na era do cinema mudo pareciam antecipar - conforme apontaram Siegfried Kracauer e outros críticos - as sombras que se aprofundariam na sociedade alemã nos anos vindouros. (KEMP, 2011, p.42)

Ainda no período entreguerras, e após o destaque dado para as criaturas fantásticas no cinema europeu (em especial o alemão, vide o já citado $O$ gabinete do doutor Caligari e $M$, o vampiro de Dusseldorf, de Fritz Lang), os estúdios de cinema da Universal, nos Estados Unidos, começou a produzir longas baseados em obras literárias pertencentes à tradição da Literatura Gótica europeia. Partindo diretamente das obras literárias ou de textos teatrais que adaptavam essas obras para o palco, esses filmes se alinharam com a situação de profunda crise econômica vivenciada pelos Estados Unidos da época. Neste cenário, os americanos iam ao cinema entrar em contato com monstros ficcionais que 
subvertiam os seus mundos e acabavam sendo derrotados pela ordem levando-os a esquecer, por algumas horas, dos horrores reais do seu dia a dia. Assim, começando por O Corcunda de Notre Dame (1923), adaptação do romance homônimo de 1831 do escritor francês Victor Hugo, a Universal começou a construir um universo cinematográfico monstruoso que teria sequência com 0 Fantasma da Ópera (1925). A partir daí, e após outras produções, a Universal entrou nos anos da década de 1930 com uma sucessão de filmes que se comunicavam com os crescentes medos da América, começando por Drácula (1931), primeira adaptação oficial do romance do irlandês Bram Stoker contando com o ator húngaro Bela Lugosi para dar vida ao senhor dos vampiros. Na sequência, e mais uma vez bebendo de fontes literárias, foi a vez de Frankenstein (1931) chegar às telas, trazendo o ator Boris Karloff para viver o monstro de Mary Shelley. Chama a atenção aqui como a força simbólica do monstro de Victor Frankenstein dentro do contexto de sua época acabou eclipsando o nome de seu criador e desde essa produção falar de Frankenstein é pensar na criatura e não no jovem cientista. Foi por conta da força dessas criações que a Universal gradualmente construiu o que ficaria conhecido como "Monstros da Universal", cuja caracterização ainda permeia o imaginário popular quando falamos de monstros. A própria criatura de Frankenstein verde com parafusos no pescoço vem dessa época, tal qual o Drácula de Bela Lugosi com sua capa, que se tornou uma indumentária típica do vampiro desde então. Para quem diz que as sequências excessivas são o pior sintoma do estado do cinema atual, vale ressaltar que essa franquia rendeu vinte e seis filmes sobre as mais variadas criaturas: vampiros, 
lobisomens, homens invisíveis e o monstro da lagoa (o qual viria a inspirar o deus-peixe de $A$ forma da água).

Paralelo às criaturas góticas, a figura do Outro também surgiu na vertente fantástica da Ficção Científica no Cinema. Disseminandose nas revistas pulp de então, quando o próprio nome "Science Fiction" passa a nomear republicações de histórias de Edgar Allan Poe, Júlio Verne e H. G. Wells, a Ficção Científica norte-americana refletiu também no Cinema o contexto racista e xenofóbico da América. O Outro aqui assume a forma de alienígenas ligados ao Oriente. Como explica Adam Roberts em A verdadeira história da ficção científica (2018) ao falar das aventuras cinematográficas de Flash Gordon nas matinês dos anos 30 contra o Imperador Ming, regente do planeta Mongo:

Não se trata, é claro, de um texto neutro no âmbito ideológico; a representação de Ming, em particular, leva a noções essencialistas de "tirania oriental e decadência", noções que são racistas e que se intensificaram em 1940, quando os Estados Unidos entraram em guerra com o Japão (embora possa ser acrescentado que, enquanto os mongonianos nas histórias em quadrinhos eram desenhados com traços raciais do Extremo Oriente, a versão para o cinema os estiliza com traços caucasianos; após o sucesso do seriado, isso também foi adotado pelos quadrinhos. (ROBERTS, 2018, p.386-387)

No pós-guerra, durante a Guerra Fria, e passada a crise econômica, a representação do Outro no cinema mainstream americano começa a direcionar-se para o chamado pânico anticomunista e a ascensão da Era Atômica. Como exemplos de filmes que retratam esse pânico anticomunista, temos $O$ monstro 
do ártico (1951), A ameaça veio do espaço (1953), Vampiros de almas (1956), Os invasores de Marte (1953) e, em especial, Guerra dos Mundos (1953), baseado no livro homônimo de H.G. Wells de 1897, o qual é visto como uma crítica pungente ao Imperialismo inglês na África e na Ásia. A versão dos anos 50, contudo, retrata o pânico anticomunista, enquanto a versão de 2005 representa os alienígenas como seres infiltrados, numa analogia ao momento de guerra ao terror vivido pelo país após o 11 de setembro. Imperialismo - Comunismo - Terrorismo. Percebe-se neste ponto como o monstro alienígena é retrabalhado para atender as angústias e receios de cada público conforme o contexto sociohistórico em que estão inseridos.

Ainda que os anos da década de 1960 tenham começado ainda refletindo a paranoia anticomunista da década anterior com o filme $O$ terror veio do espaço (1962), adaptação cinematográfica do romance $O$ Dia das Trifides, de John Wyndham, gradativamente 0 fascínio despertado tanto pelo espaço advindo da corrida espacial da Guerra Fria quanto pela crescente busca de diversas minorias por representatividade social acabaram provocando novos olhares sobre a representação do monstruoso. Assim, mulheres, negros, homossexuais e jovens norte-americanos contrários a conflitos nos quais os Estados Unidos se envolviam, passaram a subverter o status quo por meio de estratégias diversas, dentre elas, a Literatura e o Cinema. Aqui temos o abandono e a crítica à visão celebrada nos primeiros anos da Ficção Científica norte-americana propagada em revistas como a Amazing Stories e a Astonishing Stories e que encontrou sua expressão em heróis espaciais como Buck Rogers e Flash Gordon. Antes, era comum que esses emissários 
desembarcassem em algum planeta habitado por criaturas nativas e plantassem sua bandeira em nome de alguma federação planetária, desconsiderando as opiniões dos habitantes desse mesmo planeta. Esse quadro, todavia mudaria ao longo da década de 1960 quando o Outro se torna o centro da narrativa, colocado em contraste com um representante da ideologia dominante. O filme 2001: Uma Odisseia no espaço (1968) ilustra bem esse momento de desconstrução do monstruoso ao apresentar alienígenas que subvertem não apenas a sua representação física na tradição pulp, mas também que critica a pretensa superioridade cultural do ser humano (leia-se homem, anglo-saxônico, cristão) diante do universo.

Já nos anos 70, a ficção científica com seus aliens chegou ao mainstream após o impacto de 2001 e se consolidou com blockbusters como Star Wars: Uma Nova Esperança (1977), e produções que traziam visões diferentes sobre o alienígena, conforme visto em Contatos imediatos de terceiro grau (1977) e Alien, O Oitavo Passageiro (1979) - no qual este último, segundo Jordan (1984, Apud SILVA, 2010), o alienígena intruso, apresenta características como a pele negra; além de matar e infectar suas vítimas em um ato violento que remete ao estupro, em uma ação historicamente atribuída ao homem negro dentro de contextos urbanos.

Há de se dizer, ainda, que a Guerra do Vietnã em muito influenciou as produções cinematográficas dos anos 60, 70 e até 80, durante o período da chamada contracultura. Segundo o próprio George Lucas, Star Wars é uma alegoria à guerra, com os mocinhos rebeldes representando o Vietnã, e não a pátria amada chamada EUA. Apesar da dicotomia maniqueísta presente excessivamente em franquias como Rocky e Rambo (cujos inimigos eram sempre 
retratos unidimensionais de russos ou de indivíduos de qualquer outra nacionalidade cujo país de origem tivesse um posicionamento comunista, ou de qualquer maneira avesso à hegemonia estadunidense), foi possível ver, nessas décadas, vários filmes relatando os horrores da guerra e subvertendo a visão maniqueísta do comunista como o Outro absoluta e indiscutivelmente malvado e cruel, e questionando o próprio patriotismo. Há exemplos nítidos disso em variados filmes de guerra, como Apocalypse Now (1979), Platoon (1986) e Nascido para matar (1987).

Já nos anos 80, temos uma relativa "Era de Ouro" da ficção científica no cinema, na qual os filmes blockbusters começam a se consolidar graças ao sucesso de Star Wars (1977) e Tubarão (1975) na década anterior. Aqui, é preciso listar Blade Runner (1982) como um exemplo essencial de representação do Outro na ficção científica. Baseado no romance Androides sonham com ovelhas elétricas (1968), do escritor norte-americano Philip K. Dick, o protagonista do filme é um caçador de replicantes rebeldes, ou seja, androides que subverteram sua programação original. Neste universo, os replicantes são escravizados em outros planetas colonizados pela humanidade e fogem para a Terra (onde são ilegais, portanto, acabam por ser caçados e "aposentados", ou seja, mortos) a fim de tentar viver uma vida mais digna, ainda que breve e limitada. Ao final do filme, o plot twist definitivo: Deckard se descobre como o Outro que ele mesmo caça e, assim, abandona o posto de blade runner e foge com a amada Rachael, também uma replicante. Outros filmes notáveis são A mosca (1986), Aliens (1986), Predador (1987), E.T.: O extraterrestre (1982) e os outros dois filmes da primeira trilogia de Star Wars. 
Durante os anos 90, houve o início da utilização da computação gráfica de forma extensiva. Os avanços tecnológicos na área da computação permitiram que vários filmes pudessem ser feitos e tornassem realidade a imaginação de roteiristas e diretores, algo expresso no início da década em filmes como Jurassic Park (1992). Durante essa década ocorreu o apogeu dos disaster movies: grandes produções nas quais há alguma catástrofe iminente, seja a destruição do planeta através de ameaças externas (ou internas, tais como desastres naturais), seja algum desastre mais particular, como acidentes em meios de transportes (vide Titanic (1997)). Na primeira opção, encontram-se filmes como Independence Day (1996), cujo tratamento dado aos alienígenas em muito contrasta com a forma como eles são representados em filmes como Contato (1997). Mais uma vez nota-se a utilização do Outro para dar forma às ansiedades de momentos finiseculares, comumente marcada como épocas de crise de valores e convicções. Como sinaliza Jeffrey Jerome Cohen sobre o lugar do monstro no ensaio "A cultura dos monstros: sete teses" (2000): "Por sua limiaridade ontológica, o monstro aparece, de forma notável, em épocas de crise, como uma espécie de terceiro termo que problematiza o choque entre extremos" (2000, p.30-31). Ainda sobre alienígenas, o filme MIB: Homens de preto (1997) captura o lugar do Outro ocupado pelo imigrante dentro dos Estados Unidos no final do século XX no sentido de que eles de fato não pertencem ao país e, portanto, despertam suspeitas. Como explica Adam Roberts em Science Fiction (2000):

Eles são, então, estrangeiros internalizados, alienígenas disfarçados, e como tais eles representam um perigo ao corpo político, um perigo que é o trabalho dos 'Homens de Preto' 
manter sob controle. /.../ O que é claro, contudo, é que o ônus do filme representa o imigrante como visualmente do americano 'normal', e possuidor de um potencial perigoso. (2000, p.138 - tradução nossa) ${ }^{2}$

O cinema da primeira década do século XXI foi encontrar nos super-heróis o principal meio de expressão da alteridade. Ainda que adaptações de super-heróis sempre tenham marcado a história do Cinema (o primeiro super-herói adaptado para o Cinema foi o Capitão Marvel em 1941), foi a partir do início dos anos 2000 que se inicia um verdadeiro nicho cinematográfico: o "Cinema de super-herói" - o qual perdura até o momento de elaboração deste artigo - foi marcado pela produção regular e constante de longas com o tema. Os primeiros representantes desse momento são Blade (1998) e X-Men (2000).

Os X-Men, criação do quadrinista Stan Lee para a editora Marvel nos anos 60 do século $\mathrm{XX}$, traz um grupo de pessoas possuidoras de poderes especiais que os levam a serem hostilizados pelos demais seres humanos. Este grupo de super-heróis surgiu em um momento histórico de extrema tensão racial nos Estados Unidos. Esse foi o momento em que líderes negros como Martin Luther King e Malcolm X articularam estratégias de resistência e visibilidade para os afro-americanos contra a ideologia excludente da sociedade americana da época. Interessante perceber que em um primeiro momento os personagens retratavam a situação dos negros contra o racismo na América. Todavia, no universo 2 "They are, then, internalised outsiders, aliens in disguise, and as such they represent a danger to the body politic, a danger that it is the job of the 'Men in Black to keep under control. /.../ What is clear, though, is that the burden of the film represents the immigrant as visually different from the 'normal' American, and as possessing a dangerous potential." 
cinematográfico - e no novo milênio - a mensagem se alterou. No segundo filme da franquia, X-Men 2 (2003), há uma cena em que a mãe de Bobby Drake, o Homem de Gelo (Shawn Ashmore), ao se ver confrontada com a descoberta de que o filho é mutante, questiona: "mas você já tentou não ser um mutante?" (X-MEN 2 , 2003). O grupo, agora, representa os LGBTs e o tratamento a eles dispensado. Da mesma forma, em X-Men 3: $O$ confronto final (2006), o personagem anjo é confrontado pelo pai que busca uma cura mutante para o seu filho. "Você não" (X-MEN 3, 2006), diz o pai ao filho ao perceber que ele também é um mutante, em uma clara alusão à mesma situação vivenciada por inúmeros jovens que decidem se assumir como sendo LGBTs para a família conservadora. Mais recentemente, Deadpool 2 (2018) tratou da mesma questão com bastante fôlego: o antagonista do filme é um viajante do tempo que vai atrás de um garoto de 12 anos, traumatizado em uma clínica de tratamento mutante, que irá se tornar um assassino em série após matar o diretor da clínica onde estava internado. Temas como abuso sexual e terapias de conversão para LGBTs são expostos e discutidos através da temática mutante.

Alguns outros filmes dos anos 2000 e 2010 a serem notados pelo seu tratamento a respeito do Outro são Distrito 9 (2009), Guerra dos mundos (2005), Avatar (2009), No limite do amanhã (2004), A.I.: Inteligência Artificial (2001) e A chegada (2016).

\section{O CASO DE A FORMA DA ÁGUA (2017)}

Neste trabalho, será analisado o filme A forma da água (2017), dirigido pelo mexicano Guillermo del Toro, e vencedor de quatro 
Oscars (Melhor Direção, Melhor Filme, Melhor Trilha Sonora e Melhor Design de Produção).

Nascido em Guadalajara, no México, Del Toro dedicou praticamente toda sua carreira aos monstros, criaturas e histórias fantásticas. Seu primeiro longa, Cronos (1993), conta a história de um objeto místico e secular que concede - através da inoculação do veneno de uma aranha que habita em seu interior - a vida eterna a quem o detém, mas também provoca uma sede insaciável de sangue a seu portador; transformando-o, portanto, em uma espécie de vampiro. Alcançou certa notoriedade com seu terceiro longa, $A$ espinha do diabo (2001), que trata de um garoto de 12 anos deixado em um orfanato durante a Guerra Civil espanhola, o qual é recebido de forma hostil e agressiva pelas demais crianças do local e, então, recebe a visita do fantasma de um garoto assassinado no mesmo orfanato, que impele o protagonista a executar uma vingança em seu nome.

Depois, del Toro consolidou-se na indústria cinematográfica estadunidense como um nome dedicado ao Fantástico com duas adaptações de quadrinhos, lançadas em sequência. $\mathrm{O}$ primeiro filme, Blade $\|^{3}$ (2002), mal recebido pela crítica (contém, no site agregador de notas e críticas Rotten Tomatoes, uma porcentagem de aprovação, vinda da crítica especializada, de apenas 57\%, e uma nota média de 5,9 pontos em 10), é baseado em um personagem da Marvel Comics, e é a sequência de Blade (1998), uma das duas adaptações de quadrinhos da Marvel que seria a gênese do "cinema de super-herói" que vemos hoje, com superproduções de

3 ROTTEN TOMATOES. Blade II (2002). In https://www.rottentomatoes.com/m/blade_ii. Acesso em 01.Nov.2018. 
adaptações de quadrinhos das mais diversas editoras, em especial Marvel e DC. A despeito da citada má recepção crítica de Blade I/ (2002), este filme abriu as portas para que del Toro trabalhasse em outro projeto de notoriedade baseado em quadrinhos: Hellboy ${ }^{4}$ (2004). Baseado na série de quadrinhos de Mike Mignola para a editora Dark Horse, Hellboy (2004) conta a história de um demônio, invocado e materializado para a Terra, diretamente do Inferno, por nazistas, quando bebê, o qual foi descoberto pelas forças Aliadas e criado tal qual um menino humano comum por um cientista a fim de que, quando crescesse, combatesse as forças das trevas - tais quais bruxas e nazistas. Ao contrário da obra antecessora na filmografia de del Toro enquanto diretor, Hellboy (2004) foi bem recebido pela crítica (com $81 \%$ de aprovação da crítica no site Rotten Tomatoes e uma média de 6,8 pontos em 10). Hellboy (2004) também marca o início da parceria do diretor com o ator Doug Jones, que viria a encarnar várias de suas criaturas. Aqui, ele é o anfíbio Abe Sapien. Em O labirinto do fauno ${ }^{5}$ (2006), ele interpreta o fauno que dá nome ao filme, e também o enigmático Homem Pálido. Em A forma da água (2017), objeto de estudo deste artigo, é ele a criatura anfíbia mística no centro da narrativa.

O reconhecimento internacional de Guillermo del Toro como diretor, contudo, veio com o longa seguinte: $O$ labirinto do fauno (2006), o qual conta a história de uma menina de 10 anos, Ofelia, que se muda para o norte do país devido ao casamento de sua mãe com um oficial do exército. Em meio aos dramas familiares

4 ROTTEN TOMATOES. Hellboy (2004). In https://www.rottentomatoes.com/m/hellboy. Acesso em 01. Nov.2018.

5 ROTTEN TOMATOES. O Labirinto do Fauno (2006). In https://www.rottentomatoes. $\mathrm{com} / \mathrm{m} /$ pans_labyrinth. Acesso em 01.Nov.2018. 
e conflitos armados entre o exército e os rebeldes resistentes remanescentes da Guerra Civil espanhola, a garota encontra refúgio em um labirinto, vizinho à mansão onde mora, no qual descobre um submundo repleto de criaturas fantásticas, tais como o fauno do título. Indicado a seis Oscar, O labirinto do fauno (2006) saiu com três estatuetas: Melhor Fotografia, Melhor Direção de Arte e Melhor Maquiagem. Foi indicado, ainda, a Melhor Roteiro Original, Melhor Trilha Sonora e Melhor Filme Estrangeiro.

Com temas já recorrentes na filmografia de del Toro (o abandono na infância a existência de um submundo surreal e fantástico, e a Guerra Civil espanhola como pano de fundo, sendo o primeiro item e o último particularmente convergentes com $A$ espinha do diabo (2001)), O labirinto do fauno (2006) é o seu filme mais criticamente aplaudido: possui 95\% de aprovação no já citado site Rotten Tomatoes. Com um orçamento modesto de US\$19 milhões (nada comparado aos US\$54 milhões de Blade // (2002), ou os US\$ 66 milhões de Hellboy (2004)), o longa faturou quatro vezes o seu orçamento, rendendo US\$\$83 milhões ao redor do mundo, de acordo com o site estadunidense Box Office Mojo ${ }^{6}$, que agrega dados a respeito de bilheterias e orçamentos de filmes.

Os longas seguintes de del Toro ocupando a cadeira da direção foram Hellboy II: O exército dourado (2008), Círculo de fogo (2013), A colina escarlate (2015) e A forma da água (2017). Todos estes filmes têm em comum a presença de criaturas fantásticas: em Círculo de fogo (2013), criaturas monstruosas (denominadas Kaiju) despertam nos mares. Em A colina escarlate (2015), entidades misteriosas 6 BOX OFFICE MOJO. Guillermo del Toro movie box office results.In https://www. boxofficemojo.com/people/chart/?view=director\&id=guillermodeltoro.htm. Acesso em 01.Nov.2018. 
assombram a casa na qual os protagonistas moram e os atormentam. Em A forma da água (2017), que se passa durante a década de 60 do século $X X$ em uma instalação secreta de pesquisa do governo americano na cidade de Baltimore, Maryland, uma servente muda descobre uma criatura anfíbia que está sendo mantida presa em cativeiro e sofre tortura por parte de seus captores. A justificativa para esta situação é o estudo empreendido pelo governo dos EUA visando o envio de um homem ao espaço e, por consequência, a derrota dos comunistas o quanto antes. A servente, chamada Elisa, então elabora um plano junto a seus amigos para poder resgatar a criatura e libertá-lo.

No filme, há uma gama de personagens pertencentes a minorias, e as relações entre eles (e a forma como cada um deles trata outros personagens e outras minorias) é o cerne da narrativa. Elisa (Sally Hawkins) é muda, pois sofreu uma lesão nas cordas vocais quando bebê. Giles (Richard Jenkins), seu vizinho, é um gay de meia-idade solitário em um momento histórico préStonewall, em um país em que todos os estados ainda possuíam leis anti-sodomia. Zelda (Octavia Spencer), sua melhor amiga, que entende ASL (a língua de sinais americana) e faz a ponte entre Elisa e o resto do mundo, é uma negra em pleno período de apartheid americano. O Dr. Robert Hoffstetler (Michael Stuhlbarg), que tanto se interessa e simpatiza com a criatura anfíbia humanoide, é um comunista infiltrado. O grande vilão do filme, Richard Strickland, é um homem, hétero, branco, com família de comercial de margarina e masculinidade frágil, que se vê como centro do mundo e tem medo (e ódio) de tudo aquilo que é diferente de si. O filme, em sua essência, trata das relações humanas e da forma como cada 
um de nós, em nossos contextos sociais e históricos, enxergamos o Outro. O Outro "absoluto" aqui é o ser anfíbio humanoide (chamado Charley, de acordo com membros da produção do filme em postagens da internet), o qual, em sua região de origem na Amazônia, é considerado um deus, e recebe oferendas e presentes dos nativos, mas ao ser capturado pelos EUA (mais especificamente por Strickland), é alvo de tortura e ódio.

Inayatullah e Blaney (2004) afirmam que há três maneiras de se lidar com o Outro: negando-o, excluindo-o ou copiando-o. Os autores trabalham com características de Estados em um Sistema Internacional, mas é possível aplicar sua análise em contextos de análise de indivíduos.

Já Tzvetan Todorov (1999) aprofunda o problema da alteridade e o divide em três eixos:

1. Plano axiológico: plano no qual há julgamento de valor do Outro.

Ex.: o Outro é bom; o Outro é feio;

2. Plano praxiológico: plano no qual se evidencia a ação de aproximação ou distanciamento em relação ao Outro.

Ex.: adoção de valores do Outro; assimilação do Outro e imposição de outra visão;

3. Plano epistemológico: plano referente à ação de conhecer.

Ex.: opção por reconhecer a identidade do Outro como própria dele; opção por ignorar se o Outro possui identidade própria.

Aqui, analisaremos a relação dos personagens citados (Elisa, Giles, Zelda, Hoffstetler e Strickland) com o Outro - e não apenas Charley. 
1) Elisa: a protagonista se relaciona bem com todos os Outros que Ihe são apresentados, exceto por Strickland. Ela abraça e cultiva a amizade com Giles, um homem gay, e Zelda, uma mulher negra, e a despeito de sua deficiência vocal, se comunica plenamente com ambos. Ela aceita os Outros como sendo bons, assimila-os em sua vida, e reconhece e respeita a identidade deles como própria de cada um. Ela pouco interage com Hoffstetler, mas o reconhece como sendo bom (inclusive sinaliza para ele, e Zelda interpreta, "você é um homem bom, Dr. Hoffstetler"), aceita e é grata pela sua ajuda no "sequestro" de Charley, e não demonstra, em momento algum, objeção à sua identidade enquanto comunista (o qual deveria ser o "inimigo"), ou seja, o aceita. Sua relação problemática é apenas com Strickland, o qual reconhece como um homem machista e inconveniente logo no primeiro encontro, na cena do banheiro, aos 17 minutos de filme; e depois, na cena em que ele a assedia, aos 58 minutos do filme. Ao realizar esforços para a libertação de Charley, ela rejeita os valores de Strickland e, portanto, rejeita sua visão de mundo. Sua relação mais significativa, contudo, é com Charley: ao conhecer a criatura, ela (por ser ela mesma um Outro em relação aos demais personagens com quem convive, devido a sua deficiência) o vê com bons olhos, e o ensina a língua de sinais. Pode-se dizer que ela assimila-o enquanto Outro e impõe sua língua e seus gostos (apresentando-o à música), porém não o faz com a intenção de "colonizá-lo", por assim dizer, e sim, para fins de comunicação, visto que a única forma de saber se a criatura seria capaz de se comunicar era apresentá-la a algum meio de comunicação. Podemos notar aqui um breve paralelo com A chegada (2016) na forma como Elisa consegue se comunicar com Charley, enquanto 
Strickland não atinge os mesmos resultados porque foi truculento e o via como uma ameaça desde o início, enquanto no filme de Denis Villeneuve os EUA conseguem, a duras custas, se comunicar com os aliens e entender qual o propósito deles no planeta apenas após o esforço descomunal da protagonista Louise Banks (Amy Adams) em ser didática e ensiná-los a se comunicar, assim como em aprender o idioma deles; ao passo em que os demais países, que trataram os aliens como uma ameaça sem ao menos tentar conhecê-los, não alcançam os mesmos resultados. Por fim, Elisa reconhece a identidade de Charley como sendo própria dele e o defende, pois se vê nele, como é possível ver na cena da briga com Giles aos 45 minutos de filme.

2) Zelda: Zelda pouco interage com outros personagens além de Elisa e, quando há alguma interação, sua opinião tende a converger com a da amiga (ou vice-versa). Em relação a Charley, ela se mostra muito mais preocupada com a possibilidade de se envolver em encrencas do que com a segurança ou sequer o bem-estar da criatura; mas apoia as decisões de Elisa mesmo assim. Desta forma, não o desconsidera enquanto Outro, e permanece, de uma forma geral, indiferente a ele; mas contribui ativamente para que Charley seja liberto.

3) Giles: Talvez seja o personagem mais problemático dentre os personagens pertencentes a minorias apresentados neste filme. Giles é um homem gay, cuja única relação (razoavelmente) saudável com algum Outro apresentado é a que tem com Elisa: ele preza pela amizade dela, adota a sua língua de sinais, e reconhece a sua identidade enquanto mulher e muda. Contudo, mesmo aí, há problemas: na lanchonete, aos 13 minutos de filme, enquanto tenta 
impressionar o funcionário do estabelecimento, ele segura as mãos de Elisa para que ela pare de sinalizar, ou seja, sente vergonha em ser visto por um potencial par amoroso com uma pessoa deficiente. Aos 14 minutos, quando Elisa troca de canal na televisão e acaba parando em um canal de notícias que está exibindo um protesto da comunidade negra contra a segregação, provavelmente no sul dos EUA, ele ordena, agressivamente, mesmo não estando presente na sala para ver o que se passava, e tendo identificado a situação apenas pelo som, que ela mude de canal, pois não queria ver aquela "coisa horrível". Ele também se omite, aos 49 minutos do filme, quando um casal negro entra na lanchonete e é expulso pelo balconista que o havia rejeitado e o expulsaria, também, segundos depois, apenas por ser gay, da mesma forma que expulsou o casal negro apenas por serem negros. Ele se manifesta apenas após o casal se retirar do estabelecimento, dizendo "você não precisava falar assim com eles". Aos 45 minutos de filme, ele também renega a ideia de resgatar Charley, dizendo explicitamente que se trata de uma aberração, demonstrando-se incapaz de empatizar até quando Elisa traça um paralelo entre a criatura e ela mesma. Após ser acidentalmente atacado por Charley, a 1h19 de filme; ele, ao mesmo tempo em que simpatiza, também age de forma condescendente, dizendo que "ele comeu Pandora, não foi culpa dele. Ele é uma criatura selvagem, não podemos pedir que seja outra coisa.", insinuando que a criatura não possuísse racionalidade. A seguir, ele demonstra nojo ao ser tocado por Charley. Algumas cenas depois, mais especificamente 1h32, ao descobrir que Charley o havia curado através daquele mesmo toque pelo qual demonstrou nojo, ele pede a Elisa que deixe que a criatura fique com eles por mais tempo. Dessa forma, podemos 
inferir que Giles tende a renegar ao Outro, aceitando-o e vendo de forma empática somente quando Ihe for conveniente e lhe trouxer alguma vantagem.

4) Hoffstetler: No filme, Hoffstetler pouco interage com a maioria dos personagens, sendo o Outro, para ele, majoritariamente Charley e Strickland. Quanto a Charley, Hoffstetler (cujo nome, na verdade, é Dmitri) o vê com os bons olhos de um cientista que se encontra fascinado com a sua descoberta - fascínio esse que inclusive ultrapassa até a sua lealdade à Pátria Mãe, a então União Soviética, pois ele mostra-se relutante em matar a criatura quando apresentado a essa obrigação pelos demais companheiros russos infiltrados. Ele vê Charley de uma forma positiva (como diz o próprio em 1 h de filme, "uma criatura bela e complexa"), busca aproximação ao demonstrar o desejo de estuda-lo de uma forma não invasiva, e reconhece e respeita a criatura e o fato dela ser uma espécie de divinidade em sua região de origem. Quanto a Strickland, Dmitri o tem como antagonista dentro do trabalho, o vê com maus olhos, como um homem cruel, renega fortemente seus valores desde a raiz (afinal, Strickland representa os americanos, Dmitri é russo, e estão em plena corrida espacial), e opta pelo desprezo pela identidade de Strickland, em especial ao ajudar Zelda e Elisa a raptarem Charley - plano que ele mesmo não concebeu, mas que revela que gostaria de ter concebido, afinal, não lhe agradava a ideia de matar a criatura.

5) Strickland: O personagem de Michael Shannon destoa fortemente de todos os outros personagens do filme. Branco, hétero, classe média, religioso, pai de família de comercial de margarina, é esse o vilão em um filme premiado, dirigido por um dos diretores latinos 
mais conhecidos e conceituados da última década. Strickland tem uma visão extremamente limitada do Outro. Ele acha peculiar o fato de Zelda não ter irmãos e diz "isso não é comum para a sua gente", aos 26 minutos de filme, demonstrando já o que pensa sobre os negros. Um pouco depois, ainda na mesma cena, ele menciona, direcionado a Zelda, que "você pode achar que aquela coisa parece humana, porque anda com as duas pernas. Mas nós fomos criados à imagem do Senhor. E você não acha que Deus se parece com aquilo, né?", se referindo ao Charley. Quando Zelda diz que não sabe qual a aparência de Deus, ele replica, ainda, que Deus "parece humano, como eu. Ou como você. Talvez mais como eu, presumo", dando assim a entender que se vê como mais próximo e semelhante a Deus simplesmente por ser, ao contrário de Zelda, homem e branco. Aos 30 minutos de filme, ele chega a casa e é recebido pela família tradicional: esposa dona de casa, dois filhos, cenário típico de comercial de margarina. Em determinado momento, ele se senta à mesa, olha para o nada, apático; e, enquanto o resto da família se move ao fundo, diz "isso é a América". O recado do diretor não poderia ser mais claro: os EUA da família tradicional varrem diariamente para baixo do tapete a hipocrisia, junto à poeira que acumula em cima de seus móveis. Um pouco mais à frente, aos 32 minutos de filme, durante uma cena de sexo, é possível ver que ele mal encosta na esposa; o ato se torna algo mecânico, por obrigação. Quando a esposa começa a falar durante o ato sexual, ele literalmente a silencia, colocando a mão machucada e sangrenta por cima da boca dela, pedindo-a para que não fale mais. Nessa cena fica claro que, além do desprezo por negros, também há o desprezo pelas mulheres, independente da cor: ao silenciar a esposa, ele se 
isola dentro do próprio ato sexual e deixa claro que ninguém ali importa a não ser ele mesmo - seu próprio prazer é o único foco, ele crê ser o centro de todas as ações que o envolvem. Strickland passa o filme inteiro desprezando Hoffstetler pelo seu interesse em manter Charley vivo e, ao final do longa, atira no soviético, o agride e o larga na chuva para morrer. Além destas situações, há ainda que ser comentada a forma como ele vê - e trata - Charley (ou, como ele mesmo diz, "the asset": o item, o objeto, a coisa). Ele despreza a criatura em todos os níveis possíveis e a vê como um ser vivo absolutamente selvagem e nojento. Ele tortura Charley repetidamente, e perde dois dedos ao ser mordido pela criatura. É interessante notar que ele faz uma reconstrução dos dois dedos mas, mesmo assim, conforme seu ódio e sua perseguição pela criatura vão aumentando, os dedos vão necrosando até que, em determinado momento, ele mesmo os arranca, em uma clara representação visual do conceito de que sentimentos negativos nos destroem - aqui, isto ocorre de forma literal. Tal situação seria facilmente solucionável caso ele visse Charley como um Outro digno de respeito e compreensão, visto que o ser anfíbio curou Giles da calvície e de seu ferimento, mas infelizmente as informações de que Charley seria capaz de se comunicar com eles e que tem sentimentos passam completamente incólumes por Strickland, cujo ódio e desprezo por tudo aquilo que não se encaixe em seus ideais tradicionais e cristãos o cega e prejudica, levando-o a morte ao fim do terceiro ato, logo após, ironicamente, reconhecer Charley como um Deus.

Intrinsecamente ligado à história do ser humano, o monstro vem assumindo diferentes formas ao longo dos séculos sempre 
advertindo, fascinando, protegendo, refletindo, observando os rumos da cultura humana. Desde a Antiguidade, quando guardava as fronteiras do mundo conhecido e civilizado nos confins da terra até os dias de hoje, quando se torna um espelho no qual o ser humano contemporâneo vê seus medos e desejos íntimos, ele sinaliza, como em A forma da água, a necessidade do ser humano em enxergar além das utopias da igualdade entre os tipos humanos para valorizar as diferenças no processo de criação de uma sociedade tolerante, dinâmica e reconhecedora do papel da mudança como força motriz que faz a humanidade avançar.

\section{REFERÊNCIAS}

A FORMA da água (2017). Direção de Guillermo del Toro. Produção: J. Miles Dale, Guillermo del Toro. Toronto (CA): Bull Productions, Double Dare You (DDY), Fox Searchlight Pictures, TSG Entertainment.

COHEN, Jeffrey Jerome (2000). "A cultura dos monstros: sete teses". In: SILVA, Tomaz Tadeu da (Org.). Pedagogia dos monstros: os prazeres e os perigos da confusão de fronteiras. Belo Horizonte: Autêntica. (Coleção Estudos Culturais, 3), p.23-60.

GAZETA DO POVO. Apesar do que diz a Disney, Star Wars sempre foi político. In https://www.gazetadopovo.com.br/caderno-g/cinema/apesar-do-que-diza-disney-star-wars-sempre-foi-politico-cvab5t1e4dk64ievglvifo2cj. Acesso em 09.Jul.2018.

INAYATULLAH, Naeem; BLANEY, David (2004). International Relations and the Problem of Difference. Routlege.

KEMP, Philip (2011). (Org.) Tudo sobre cinema: Inglaterra. Rio de Janeiro: Sextante.

ROBERTS, Adam (2018). A verdadeira história da ficção científica: do preconceito à conquista das massas. Mário Molina (Trad.). São Paulo: Seoman.

ROBERTS, Adam (2000). Science Fiction. New York: Routledge, (The New Critical Idiom). 
SCHOEREDER, Gilberto (1986). Fiç̧ão Científica. Rio de Janeiro: Francisco Alves. SILVA, Alexander Meireles da (2010). "Além dos homenzinhos verdes: a representação da monstruosidade alienígena no fantástico afro-americano". In II COLÓQUIO NACIONAL DE ESTUDOS EM NARRATIVA: história e ficção no universo do fantástico. Uberlândia.

TODOROV, Tzvetan (1999). A Conquista da América: a questão do Outro. Beatriz Perrone Moisés (Trad.). 2.ed. São Paulo: Martins Fontes. 